\title{
QUEM ÉRAMOS NÓS, PROFESSORES MODERNOS DE MATEMÁTICA?*
}

\author{
Elisabete Zardo Búrigo
}

\section{Resumo:}

A partir de reflexões sobre identidades e estranhamentos em narrativas autobiográficas, a autora examina textualizações de depoimentos orais de professores sobre o chamado movimento da Matemática Moderna, nas décadas de 1960 e 1970, no Brasil, buscando identificar, nessas narrativas, representações do possível, do (im)provável e do acaso. A noção de ação humana segundo Hannah Arendt é mobilizada para a discussão sobre como os professores representam sua agência ou perspectiva frente ao movimento. Na releitura dos depoimentos, percebe-se que a maioria dos participantes não fazem referência ao acaso: para uns, trata-se, ainda, de agir e intervir em um processo inacabado; para outros, não há acaso e nem sequer imprevisibilidades - pois tudo aconteceu conforme previram e advertiram. As menções a "sorte" e "coincidência" aparecem conectadas à perspectiva de ver-se, com algum estranhamento, como um agente de uma história ocorrida no passado; pois se a ação humana é a realização do improvável, também é a afirmação do possível.

Palavras-chave: História da Educação Matemática; Memórias; Matemática Moderna.

O título deste capítulo parafraseia um artigo de Wagner Rodrigues Valente que apresenta elementos de uma genealogia do professor de matemática no Brasil. Imita, ainda, um título de coletânea - "Osvaldo Sangiorgi: um professor moderno".

A inflexão temporal - ao invés de "quem somos", "quem éramos" - remete ao passado; mas a pergunta alude ao perguntador ou à perguntadora, que se interroga no presente. Pressupõe um estranhamento e, ao mesmo tempo, uma atribuição de identidade. De um lado, a pergunta envolve aceitar a conjectura de que já não somos aqueles professores que tomamos agora como objeto de interrogação; marca um afastamento em relação àqueles personagens de outro tempo, que não apenas se moviam em outras circunstâncias, mas talvez com outras intenções ou preocupações. De outro lado, a primeira pessoa do plural, o "nós" implícito na questão, faz referência a um sujeito ou a muitos sujeitos, agentes do seu tempo, de quem talvez possamos nos aproximar. Ainda, a evocação do "nós" supõe a busca de alguma identidade ou, pelo menos, uma conexão entre aqueles sujeitos do passado. Finalmente, com a expressão "modernos" queremos aludir a professores engajados no movimento da matemática moderna no Brasil.

Neste capítulo, proponho reexaminar depoimentos de educadores matemáticos brasileiros sobre sua participação no movimento da Matemática Moderna. O estranhamento - "quem éramos" - é um elemento comum a narrativas produzidas desde o final dos anos 1980, relativas a eventos e engajamentos dos anos 1960 e 1970. Pois as avaliações então correntes de um "fracasso", de uma imposição ou de um equívoco da

\footnotetext{
* DOI - 10.29388/978-65-86678-51-2-0-f.297-316
} 
Matemática Moderna (BÚRIGO, 1989), e as reações a esses discursos suscitaram interrogações, debates e provocaram muitos daqueles professores a interpretar ou reinterpretar ações e escolhas feitas no passado.

O que tudo isso tem a ver com o acaso, tema desta coletânea? A proposta deste texto é identificar, nessas narrativas, representações do possível, do provável e do improvável, e ainda do acaso, como aquilo que, tendo ocorrido - e, portanto, tendo sido possível - não fora previsto, planejado e talvez nem mesmo imaginado.

Em 1988 e 1989, tendo tomado a Matemática Moderna como objeto de estudo acadêmico, realizei entrevistas com professores que, nas palavras de Irineu Bicudo (apud BÚRIGO, 1990), foram "militantes" do movimento. Outros e outras colegas, antes e depois, também colheram depoimentos orais sobre o tema. O Grupo de Pesquisa em História da Educação Matemática no Brasil (GHEMAT) organizou e gravou, em áudio e vídeo, mesas-redondas com professores que participaram do Grupo de Estudos em Ensino de Matemática (GEEM ${ }^{53}$. Assim, contamos hoje com um vasto material composto de depoimentos de memória sobre o movimento da Matemática Moderna no Brasil.

Para este capítulo, escolhi tomar como objeto de exame a textualização de uma mesa-redonda realizada em 2003, no V Seminário Nacional de História da Matemática, em Rio Claro, com o tema "O ensino de Matemática nas décadas de 60 e 70 (século XX) no Brasil: projetos pedagógicos e produção de livros didáticos”. Para essa mesa, foram convidados os professores Rui Madsen Barbosa (coordenador dos trabalhos), Lafayette de Moraes, Scipione de Pierro Neto e as professoras Lourdes de la Rosa Onuchic e Martha Maria de Souza Dantas. O papel atribuído aos participantes, na composição da mesa, teria sido o de historiadores ou de narradores de memórias? Não temos acesso à introdução dos trabalhos, feita pelo professor Rui. Mas, ao longo de suas participações, todos os professores implicam a si mesmos nos eventos dos anos 1960 e 1970 e, em particular, no chamado movimento da Matemática Moderna; todos apresentam interpretações ou explicações para os eventos da época. De algum modo, todos se acercam da pergunta: "Quem éramos nós, professores modernos de Matemática?".

\section{Sobre a viabilidade do discurso (auto)biográfico}

Em seu emblemático texto " A ilusão biográfica" "54 , Bourdieu (2006) interroga a noção de "história de vida" e sua admissão, a partir do senso comum, nos estudos sociológicos. Para o autor, narrar uma história de vida pressupõe conceber que "[...] a vida constitui um todo, um conjunto coerente e articulado, que pode e deve ser apreendido como expressão unitária de uma 'intenção' subjetiva e objetiva” (BOURDIEU, 2006, p. 184). O sociólogo francês argumenta que é impossível compreender o sentido dos movimentos que compõem uma trajetória sem considerar "[...] o conjunto das relações objetivas que uniram o agente considerado [...] ao conjunto dos outros agentes envolvidos no mesmo campo e confrontados com o mesmo espaço dos possíveis" (BOURDIEU, 2006, p. 190). Nas

\footnotetext{
${ }^{53}$ No site do Centro de Documentação do GHEMAT - https://www.ghemat.com.br/centro-de-documentacao - é possível acessar as entrevistas realizadas em 1988 e 1989, para minha dissertação, em arquivos de áudio, e os registros dessas mesas-redondas, em vídeo.

${ }_{54}$ Publicação original: BOURDIEU, P. L’illusion biographique. Actes de la Recherche en Sciences Sociales, v. 62-63, p. 69-72, jun. 1986.
} 
histórias de vida, aponta o autor, a investigação dessas conexões é substituída pela aceitação de que os elos importantes poderiam ser encontrados em uma artificial sequência de acontecimentos dos quais o biografado participou, ou que protagonizou.

Interrogando, por sua vez, a investida de Bourdieu, Oliveira (2017) reconhece como inerente ao trabalho do biógrafo a interrogação sobre a "pertinência da atribuição de sentido e inteligibilidade a uma vida narrada como história", e o dilema vivido face ao "suposto caráter coeso e invariável do sujeito biografado e a notória multiplicidade de contradições e incongruências que caracterizam uma existência individual" (OLIVEIRA, 2017, p. 442). Uma solução para o dilema, proposta por Ricoeur, seria a ipseidade, outra modalidade de permanência no tempo, que não a da suposta constância do caráter, mas a de uma manutenção e atestação de si que se constitui como uma vontade de identidade mantida a despeito da mudança.

Podemos pensar que a questão já enunciada - "quem éramos" - de algum modo pressupõe essa atestação de si, pois a interrogação só faz sentido quando existe uma permanência que possibilita uma evocação e reflexão do que se viveu.

\section{Ação humana, o improvável e a imprevisibilidade}

Hanna Arendt (2007) reflete sobre a ação como atividade humana que se distingue das demais pela agência e pela singularidade: "Na ação e no discurso, os homens mostram quem são, revelam ativamente suas identidades pessoais e singulares, e assim apresentamse ao mundo humano [...]" (ARENDT, 2007, p. 192). Na ação, a pessoa revela "quem é"; é por meio de sua história ou biografia que podemos saber quem um homem foi. Mas essa revelação não é planejada, pois ninguém pode dispor de "quem" é, do mesmo modo como dispõe de suas qualidades, e é provável, na perspectiva da filósofa, que o "quem" permaneça invisível para a própria pessoa.

Arendt refere-se à ação como a realização do improvável: "O novo sempre acontece à revelia da esmagadora força das leis estatísticas e de sua probabilidade que, para fins práticos e cotidianos, equivale à certeza; assim, o novo sempre surge sob o disfarce do milagre" (ARENDT, 2007, p. 191). A ação incide sobre uma teia de relações humanas já existente, e é em virtude dessa teia, “[...] com suas inúmeras vontades e intenções conflitantes, que a ação quase sempre deixa de atingir seu objetivo" (ARENDT, 2007, p. 196), mas é também graças a esse meio, e às reações suscitadas, também imprevisíveis, que a ação "produz histórias" que podem ser depois registradas e recontadas. Devido à imprevisibilidade, não se pode confundir agência e autoria, sujeito e autor; pois, como Arendt frisa, ação não se confunde com fabricação. Embora se possa muitas vezes identificar um agente principal de um processo, ninguém é autor de sua própria história: "A história real, em que nos engajamos durante toda a vida, não tem criador visível nem invisível porque não é criada” (ARENDT, 2007, p. 198). Assim, para Arendt, “[...] a luz que ilumina os processos da ação e, portanto, todos os processos históricos, só aparece quando eles terminam" (ARENDT, 2007, p. 204). Ela arremata: “A ação só se revela plenamente para o narrador da história, ou seja, para o olhar retrospectivo do historiador, que realmente sempre sabe melhor o que aconteceu do que os próprios participantes" (ARENDT, 2007, p. 204-205). 
$\mathrm{Na}$ perspectiva de Arendt, pode fazer sentido a pergunta "quem éramos?"? Sim, se aceitarmos que o processo do qual se está falando já se encerrou, pelo menos do ponto de vista daqueles que se interrogam. $\mathrm{O}$ inquiridor poderia ver a si mesmo, no passado, como agente de uma história que já se pode vislumbrar, pois suas consequências já são conhecidas ou conhecíveis. Podemos inferir que, nessa perspectiva, ao contrário da continuidade artificial denunciada por Bourdieu, o pressuposto da biografia seria a descontinuidade: pois não podemos saber quem somos, mas talvez possamos saber quem fomos, ao estranhar e estudar os processos em que estivemos envolvidos e dos quais fomos agentes ou sujeitos.

Nessa perspectiva, cabe a ideia já referida da ipseidade? Ao longo do texto, procuraremos esboçar alguma aproximação de resposta a esta questão.

\section{Mesa-redonda - a primeira rodada de manifestações dos participantes}

A mesa-redonda que dá origem ao material aqui examinado foi realizada em 2003, e gravada em vídeo. A textualização foi produzida, alguns anos depois, pelo Grupo de Pesquisa "História Oral e Educação Matemática" (GHOEM), revisada e publicada por Antonio Vicente Marafioti Garnica (2008). Os comentários e extratos citados nesta seção seguem a ordem dos depoimentos dos professores, durante o debate e na referida textualização. Há, certamente, infindáveis possibilidades de recortar e de ler esses extratos; o recorte e a leitura que aqui apresento resultam de escolhas - umas mais intencionadas, outras nem tanto.

Em sua fala inicial, Lafayette de Moraes apresenta-se como um professor que, nos anos 1960, trabalhava na Fundação Brasileira para o Desenvolvimento do Ensino de Ciências (FUNBEC), tendo sido esse o motivo para realizar um estágio nos Estados Unidos, e depois traduzir e adaptar materiais do School Mathematics Study Group (SMSG), criado em 1958 sob a liderança de E. G. Begle, então professor da Yale University (BEGLE, 1959). As escolhas envolvidas nos materiais que produziu são, inicialmente, imputadas ao SMSG:

O SMSG, depois de várias discussões, chega à seguinte conclusão: a gente faz aquela Matemática tradicional da Aritmética, Álgebra, Geometria, Trigonometria, e a gente tem que mudar esse enfoque, tem que ver a Matemática sob outro enfoque. Depois esse enfoque foi bastante criticado, mas, enfim... e esse enfoque qual seria? Então seria dar ênfase às estruturas. Então a gente dava estruturas (MORAES, apud GARNICA, 2008, p. 169).

Lafayette também relata que ministrou cursos, que descreve como uma necessidade ou, pode-se inferir, como resultado de uma escolha feita por outrem: "E os professores, naquele tempo, praticamente ninguém tinha contato com essas noções, a definição de função por meio de conjuntos. Tỉnham que ser treinados. Então nós promovemos um volume enorme de cursos chamado de "reciclagem de professores" (MORAES, apud GARNICA, 2008, p. 170). O relato de uma agência, de um engajamento, tem início quando fala da adaptação de materiais do SMSG: 
Então, com o tempo, a gente foi tentando fazer, modificando uma porção de coisas e apresentando os textos que, por sua vez, também não eram muito atraentes porque, por questão de economia, a impressão dos textos do SMSG deixava muito a desejar, principalmente para as primeiras séries do chamado, naquele tempo, de Curso Ginasial. Então a gente procurou fazer, dentro das limitações, o que era possível. [...] O Livro do Professor, que ele [professor participante de curso de reciclagem] recebia gratuitamente, era mais volumoso do que o livro recebido pelo aluno, e conseqüentemente isso encarecia bastante. Mas foi uma maneira que a gente teve para, praticamente, convencer (entre aspas) as pessoas a adotarem a nova metodologia (MORAES, apud GARNICA, 2008, p. 170).

Lafayette apresenta-se, então, como autor dessas produções:

[...] enfim, logo depois fui para UNICAMP, no IMECC, e eu ficava muito satisfeito quando alguns alunos do Instituto diziam - 'Olha, eu comecei a gostar de Matemática quando peguei os textos do SMSG e eu tive acesso ao Livro do Professor e o Livro do Professor me abriu uma porção de horizontes'. Naquele tempo eu ouvi muitas vezes isso e fiquei muito satisfeito (MORAES, apud GARNICA, 2008, p. 171).

O encerramento do processo é atribuído a uma "fatalidade", um evento cuja ocorrência não foi planejada nem poderia ser evitada pelos agentes envolvidos nos cursos e produções de materiais:

Em 64 todo mundo sabe o que houve aqui - uns chamam de revolução, outros chamam de golpe - mas o fato é que com isso todos os planos educacionais da FUNBEC (cujo diretor, naquele tempo, era o Isaias Raw, que logo depois foi cassado) foram por terra e houve então uma mudança grande. A coleção do SMSG que, em sua fase inicial, tinha programado uns vinte volumes, parou mais ou menos no décimo quinto, e surgiram então os livros comerciais... (MORAES, apud GARNICA, 2008, p. 171-2).

Ao final de seu depoimento, Lafayette reitera o protagonismo do SMSG, que identifica como um sujeito histórico, que propõe e provoca mudanças. Ao mesmo tempo, modestamente, fala da "sorte" de ter colaborado com o grupo:

Mas, em princípio, o SMSG teve essa, vamos dizer, mudança de visão, esse papel histórico com o qual, pelo menos, a gente teve a sorte de colaborar um pouco (MORAES, apud GARNICA, 2008, p. 171).

Ainda que atribuindo a si mesmo um papel secundário - "colaborar um pouco" nessa finalização, ele se apresenta como, de algum modo, identificado ou integrado ao SMSG.

Diferente é a perspectiva de Lourdes Onuchic, que se refere à Matemática Moderna como um empreendimento de outros agentes, que sempre criticou:

Já em 1951, nos Estados Unidos, se pensava nesta mudança de fazer uma Matemática estruturada, feita por matemáticos que não tinham quase contato com a sala de aula 
e que, sem apelar a nenhum conhecimento dos professores, institui uma Matemática toda estruturada, apoiada em estruturas algébricas, topológicas e, assim, fazendo tudo isto, introduzindo na notação altamente sofisticada, introduzindo formas de se falar e preparar que não atingiam nem os professores e nem os alunos, inclusive cometendo uma grande coisa que eu sempre achei errada [...] (ONUCHIC, apud GARNICA, 2008, p. 173).

Para a discussão trazida neste texto, vale observar que a professora Lourdes relata uma permanência de suas opiniões sobre a Matemática Moderna: “[...] eu sempre achei errada”. Retrata a si mesma, nos anos 1960, como vendo os problemas do mesmo modo como os percebia naquele momento de participação na mesa-redonda, e até sendo capaz de prever efeitos nefastos das mudanças então propostas:

Então os pais deixaram que essa Matemática fosse feita na escola, por professores que também não sabiam fazer, pois eles não haviam sido preparados. Apresentaram o material pronto para que eles trabalhassem nisto. E isto eu acho que foi um dos grandes crimes, uma mudança sem observar que estas coisas poderiam acontecer (ONUCHIC, apud GARNICA, 2008, p. 173-174).

Ela relata que, vivendo nos Estados Unidos desde 1962, participou de dois cursos na universidade Johns Hopkins, um sobre Aritmética na escola elementar e outro sobre Matemática na escola secundária:

[...] era tudo em termos de Lógica, tudo em termos de estruturas, tudo em termos de propriedades, aquilo que eu havia aprendido quando fui para a faculdade - a teoria dos conjuntos - e lá nós tínhamos que trabalhar com crianças desde o pré-primário (ONUCHIC, apud GARNICA, 2008, p. 175).

Nesses cursos, defrontou-se com o inesperado, um inesperado relatado como inelutável:

Aquilo para mim foi um choque quando me vi diante daquela situação, tendo que trabalhar com crianças aqueles conceitos todos que não faziam parte nem da sua vida, nem da vida da maioria dos pais. Bem, mas fiz os cursos (ONUCHIC, apud GARNICA, 2008, p. 175).

A mesma condição de quem sofre os efeitos da ação de outros é enfatizada quando relata seu trabalho com professoras primárias em Rio Claro, ainda nos anos 1960. Lourdes refere-se à Matemática Moderna como uma imposição:

E durante dois anos eu trabalhei começando a Matemática com a Aritmética com compreensão de Spitzer, trabalhando com outras coisas e começando com as idéias da Matemática Moderna. Por quê? Logo, logo, nós tivemos encontros, aqui no Brasil, um colóquio que se realizou em São José dos Campos, em que ficou lá tudo muito bem imposto: tudo o que se falava de Matemática Moderna seria trabalhado obrigatoriamente no norte, sul, leste, oeste do país (ONUCHIC, apud GARNICA, 2008, p. 176). 
O relato, entretanto, dá conta de que, mesmo em um contexto de imposição, havia ainda margem para a ação. A agência mencionada na narrativa de Lourdes não era de defesa nem de contestação da Matemática Moderna, mas a de alguém que percebia sua participação como necessária, fazendo as escolhas possíveis naquele ambiente:

Então, mais uma vez, eu [...] fui trabalhar Matemática Moderna com uma porção de professores, numa porção de ocasiões. Muitos encontros, muito trabalho e aquela Matemática Moderna em plena evolução, todo mundo tendo que trabalhar aquilo e a maioria das pessoas não sabendo (ONUCHIC, apud GARNICA, 2008, p. 177).

Embora Onuchic insistisse em não se identificar como proponente da Matemática Moderna, tendo considerado um erro sua implementação, envolvendo "grandes crimes" e ficando "tudo muito bem imposto", ela tampouco é autora das críticas "violentas" feitas à época do movimento:

\begin{abstract}
Muitas críticas houve nesse caminho, e as críticas todas que se fizeram à Matemática Moderna começaram a produzir um certo resultado: as críticas levaram a que se voltasse a pensar em certas idéias construtivistas, que se visse alguma coisa a mais, que se pensasse em alguma coisa. $\mathrm{E}$ as críticas foram de tal maneira violentas que acabaram gerando o que a gente costuma chamar do fracasso da Matemática Moderna. Mas muita coisa tinha sido desgastada. Mas não era tudo ruim, não era (ONUCHIC, apud GARNICA, 2008, p. 177).
\end{abstract}

Seu papel, além de atuar no que pode ser interpretado como "redução de danos", formando professores, era o de alertar para os riscos do empreendimento em que outros, ousada mas inadvertidamente, se engajavam:

Bem, quando nós recebemos esse convite para o congresso que houve em São José dos Campos era um sucesso, era um encontro assim com gente de muito bom nome, Marshall Stone, Papy, um monte de gente trabalhando para fazer aquilo. E eu me lembro que perguntei: - "Gente, e os professores que vão trabalhar com isto?" $\mathrm{E}$ ficou no ar. Havia uma pendência, todos estavam assustados com a perspectiva do que pudesse vir a partir daquilo (ONUCHIC, apud GARNICA, 2008, p. 178).

Ao longo de sua fala, Lourdes sugere que, após o "choque" do início, todos os efeitos da Matemática Moderna teriam sido previstos por ela antecipadamente. Mas, ao final do depoimento, aponta que, apesar desse olhar distanciado e precavido, o movimento impactou sua trajetória:

E muitas vezes, em palestras a que me convidavam, eu não podia expressar alegria por aquela maneira de trabalhar quando eu via os professores tão despreparados. E isto me levou a pensar em outros caminhos, como é o caminho em que eu trabalho agora (ONUCHIC, apud GARNICA, 2008, p. 179).

Podemos pensar, então, que Lourdes teria sido uma espectadora da Matemática Moderna, e que a ação por ela reivindicada é posterior ao movimento, quando pôde pensar e construir outros caminhos.

Diferentemente dos demais, Martha Dantas leu extratos de um texto que havia preparado de antemão. Ao lermos esses extratos, percebemos que não estava preocupada 
apenas em usar palavras adequadas ou em registrar informações que não queria esquecer de mencionar. Sua narrativa apresenta elementos de um discurso articulado sobre um movimento no qual se retrata como protagonista. Ela inicia falando das motivações para organizar e convocar o I Congresso Nacional de Ensino da Matemática do Curso Secundário, em 1955, em Salvador. Já nesse evento, podemos identificar o que Hanna Arendt refere como o improvável: pois se o contexto dos anos 1950 era favorável à sua realização, o Congresso não decorre de nenhum processo em andamento antes disso. Resulta de uma iniciativa de Martha Dantas e do acolhimento - imprevisível - dessa iniciativa por pares, professores de Didática da Matemática nas Faculdades de Filosofia e professores de Matemática nas escolas secundárias. Dentre os efeitos - também imprevisíveis - desse evento, destaca a fundação do Instituto de Matemática e Física (IMF) da Universidade Federal da Bahia (UFBA), em 1960, e a direção do Instituto pelo matemático Omar Catunda, vindo de São Paulo, a partir de 1963. Puxando um outro fio da trama que articula sua narrativa, Martha fala de inquietações de professores secundários nos anos 1950, e das respostas então produzidas pela Comissão Internacional para Estudos e Melhoria do Ensino da Matemática (CIEAEM), constituída por matemáticos, pedagogos, psicólogos e um lógico matemático que, publicadas em 1955, "confirmavam a possibilidade de introduzir a chamada Matemática Moderna na escola secundária" (DANTAS, apud GARNICA, 2008, p. 184).

No relato de Martha, esses são elementos que preparam e possibilitam a proposição de um projeto modernizador construído por professores da UFBA, nos 1960:

A década de 50 foi palco de projetos audaciosos para o ensino da nova Matemática, e as publicações para alunos e professores se sucederam, e a experimentação se estendeu pela década de 60. Foi nesta década que decidimos, na Bahia, participar das mudanças solicitadas pela referida Comissão e, sob a coordenação do professor Catunda, um grupo de professores da UFBA elaborou um projeto de Matemática Moderna a que se intitulou Desenvolvimento de um Currículo para Ensino Atualizado da Matemática em Ensino Médio (DANTAS, apud GARNICA, 2008, p. 184).

Martha Dantas retrata a si mesma como agente e autora. Agente, engajada na proposição e implementação do projeto; autora, participante de uma produção coletiva, que não se confundia com a reprodução ou tradução de outros textos:

Embora conhecêssemos bem as experiências da França e da Bélgica, não pretendemos, em momento algum, seguir de perto as suas programações. Queríamos algo que se ajustasse às nossas posições locais e acabamos por consegui-lo. Buscamos um consenso geral sobre os conceitos introduzidos. Não foi difícil encontrá-lo, levando em consideração as recomendações de reuniões internacionais, interamericanas e nacionais. Naquela época, por exemplo, os conceitos de relação e de estrutura encabeçavam as listas de conteúdos que deveriam ser introduzidos, o mais cedo possível, nos programas de primeiro grau. Outros conceitos, tais como de transformação geométrica, linearidade, probabilidade, estatística, bem como noções de lógica, topologia, eram também recomendados, quer pelo seu valor pedagógico, quer pela sua aplicabilidade. [...] As transformações geométricas constituem também o melhor meio para introduzir Geometria aos conceitos de semelhança e congruência de figuras. E Catunda aceitou usá-las para abordar Geometria Euclidiana. Quanto à Lógica, eram recomendadas apenas noções que permitissem ao aluno definir bem as 
coisas e familiarizar-se com as formas de raciocínio indispensáveis ao emprego do método axiomático. A linearidade, um dos conceitos mais importantes da Matemática, teve a sua introdução também recomendada no primeiro grau (DANTAS, apud GARNICA, 2008, p. 184-185).

A agência dos professores é destacada, quando Martha relata que iniciaram os trabalhos de redação de materiais para uma experimentação em sala de aula sem qualquer suporte institucional, sugerindo que o suporte mais tarde possibilitado pela criação do Centro de Ensino de Ciências da Bahia (CECIBA) teria sido, de algum modo, conquistado pelo grupo:

Era preciso elaborar textos experimentais. Como a UFBA não nos liberou para isso, assumimos essa tarefa por conta própria. Felizmente, em 1966, quando já tínhamos redigido os textos para a quinta, sexta e sétima séries e estávamos começando a redigilos para a oitava série, acabavam de ser criados no Brasil os convênios entre o MEC, Secretarias da Educação, Universidade e Centros de Ensino de Ciências, e na Bahia instalou-se o CECIBA. O grupo foi convocado para trabalhar no CECIBA, sendo a coordenação do setor de Matemática assumida por mim. Demos especial destaque ao projeto Desenvolvimento do Currículo para Ensino Atualizado da Matemática em Nível Médio, no qual já estávamos trabalhando e para o qual já tínhamos elaborado texto sobre a coordenação do professor Omar Catunda, os quais foram publicados pela editora Edart, de São Paulo (DANTAS, apud GARNICA, 2008, p. 185-186).

Ainda que "seguir de perto as suas programações", Martha menciona a contribuição, para as ações de formação de professores empreendidas pelo CECIBA, do Centro Belga de Pedagogia de Matemática, onde haviam estagiado as professoras Eliana Costa Nogueira, Neide Clotilde de Pinho e Souza, Eunice da Conceição Guimarães e Norma Coelho de Araújo. Ela reivindica essa referência: “o professor Papy realizava, naquela época, a mais audaciosa tentativa para introduzir a Matemática Moderna no ensino secundário. A Geometria das transformações era o ponto alto das programações do Centro Belga" (DANTAS, apud GARNICA, 2008, p. 186).

Martha reivindica, ainda, uma avaliação exitosa da experimentação iniciada em 1966, no Colégio de Aplicação da UFBA. Novamente ela assume, declaradamente, a agência nesse processo, e explica as condições que teriam possibilitado esse êxito, estimadas e confirmadas ao longo da experimentação:

Elaborados os programas, redigidos os textos e preparados os professores que participaram dos cursos, procedeu-se à aplicação desses textos. Estas programações, que poderiam parecer utópicas para os que ainda não tinham vivência de ensino que utilizava noções fundamentais da chamada Matemática Moderna, foram bem sucedidas quando da aplicação dos referidos textos a partir de 66 no Colégio de Aplicação da Universidade Federal da Bahia. A experiência foi considerada de alto nível, mas não fracassou porque os professores que a realizaram no referido colégio estavam preparados para ela e os alunos que dela participaram tinham condições de suportá-la (DANTAS, apud GARNICA, 2008, p. 186).

A agência do grupo proponente produzia efeitos e também era afetada pelos participantes da experimentação - a ação provocando o imprevisível, o imprevisível provocando a ação: 
Ciente de que toda experiência inovadora precisa ser seguida de perto e ser constantemente reavaliada, começamos de imediato, baseados na reação dos alunos em sala de aula e na análise crítica que dessa reação faziam os professores engajados na experiência, a modificar os testes. A tendência à abstração que marcou inicialmente as nossas programações precisava ser reduzida. Era preciso eliminar conceitos muito abstratos para os alunos e encontrar abordagens mais intuitivas para conceitos que julgamos deveriam permanecer. As críticas que internacionalmente passaram a ser feitas ao ensino da Matemática Moderna recomendavam mais e mais o retrocesso do caráter abstrato formal e dedutivo com que se tratavam as estruturas matemáticas, sugerindo uma maior concentração sobre a sua compreensão e sua aplicação. Recomendava-se, por exemplo, omitir o estudo explícito da Teoria de Grupos, podendo, no entanto, manter atividades e aplicações que ilustrassem essa estrutura. E a análise crítica do projeto continuou. Ele foi reestruturado. Novos programas foram elaborados, novos textos foram redigidos (DANTAS, apud GARNICA, 2008, p. 186-187).

Martha indica que teria, como tantos outros agentes, aprendido com o processo. Seu ponto de vista parece ter se construído nas reflexões que precederam e que foram desenvolvidas ao longo do processo, nos anos 1960 e 1970: "Não fossem essas experiências de pesquisa e até hoje estaríamos sem saber por que rejeitar a Matemática Moderna e em que medida ela deveria ser rejeitada, definindo o que era preciso ser conservado de tudo que foi feito" (DANTAS, apud GARNICA, 2008, p. 187).

Dialogando com as críticas à Matemática Moderna, Martha reivindica o caráter progressista do movimento, por ter substituído ou pretendido substituir a "velha matemática":

Embora seja razoável fazer crítica à Matemática Moderna, o seu fracasso não justifica uma volta ao ensino da velha matemática. A Matemática Moderna foi pensada para enriquecer a velha Matemática e substituir certos aspectos arcaicos desta com materiais mais relevantes para os propósitos e necessidades de hoje. Na prática, não se pode dizer que a Matemática Moderna realizou estes objetivos. Há muitas explicações para isso e vale a pena abordar este assunto com muito cuidado e detalhes (DANTAS, apud GARNICA, 2008, p. 189).

Sobre essas críticas, Martha propõe ainda algumas precisões e reparos:

Acompanhando de perto o processo de mudanças operadas nas décadas de 50, 60 e 70 , acho que se faz necessária uma análise cuidadosa para que se ponha um ponto final em mudanças radicais. Os apelos da década de 50 para entregar ao aluno da escola secundária a Matemática pronta com a qual lidam os matemáticos não devem ser substituídos, hoje, pelos apelos para lançar abaixo todas as conquistas que o novo modo de produzir a Matemática alcançou. Os apelos de René Thom, Peter Hilton e outros matemáticos que não foram aqui citados não são pela volta da velha Matemática. Eles reconhecem que a Matemática mudou e que novos conceitos devem ser introduzidos. O que eles condenaram é o modus faciendi. René Thom não condena o uso da linguagem dos conjuntos e, sim, que se faça teoria dos conjuntos onde esta não procede. Mas o que não tem sido divulgado - e é muito importante na declaração de René Thom - é o reconhecimento que ele faz do fosso que existe entre a Educação Matemática de nível médio e de nível superior, fosso este que, segundo ele, os jovens, saindo da escola secundária, têm dificuldade de transpor. Para ajudar a vencer essa dificuldade é o próprio Thom que propõe, como acabamos de ver, a 
introdução, na escola secundária, da notação de conjuntos e rudimentos de álgebra linear (DANTAS, apud GARNICA, 2008, p. 190).

Enfim, a professora aponta que o projeto desenvolvido desde 1966 foi reestruturado, perante as críticas à Matemática Moderna:

As críticas internacionais feitas à introdução da Matemática Moderna em nível médio ultrapassaram as raias do bom senso. Era difícil manter o projeto em pauta, mas os matemáticos que foram aqui citados não condenaram a introdução de novos conceitos, e sim o modus faciendi. Então nos perguntamos: como conceder o modus faciendi adequado? [...] E uma luz surgiu no túnel e pensamos: se conseguirmos levar o aluno a estudar sozinho, ele será capaz de utilizar diferentes fontes de informação e recursos tecnológicos que lhe permitam aprender o novo. Capacitá-lo para aprender o novo é certamente muni-lo com um dos mais valiosos recursos para enfrentar situações novas para sobreviver neste momento histórico. Agindo assim, estaríamos certamente deixando de pensar demasiadamente na Matemática para pensar suficientemente no aluno. Como se prepara o aluno para estudar sozinho? Entregando-lhe textos que desenvolvam seu pensamento crítico e criativo que enfatizem os porquês e utilizem processos que harmonizem a exposição com a descoberta. Concebendo assim, pudemos reestruturar o Projeto Desenvolvimento de um Currículo para Ensino Atualizado da Matemática em Nível Médio, substituindo pelo projeto para a melhoria do ensino da matemática de quinta a oitava séries (DANTAS, apud GARNICA, 2008, p. 190-191).

Scipione di Pierro Netto, à semelhança de Lourdes Onuchic, fala do movimento da Matemática Moderna do lugar de um espectador. Reproduzindo uma versão bastante disseminada - de que a movimentação da Matemática Moderna teria sido provocada pelo lançamento do satélite Sputnik - e misturando episódios ocorridos em 1957, 1961 e 1968, Scipione ironiza a surpresa dos norte-americanos frente ao avanço soviético, no contexto da Guerra Fria, descrevendo-a como um "susto" e sugerindo que a reação ao "susto" teria levado a um encadeamento de ações mal planejadas.

A Matemática [Moderna] nasceu de um susto, o susto que os americanos levaram quando o Gagarin lá em cima disse: "A Terra é bela, é azul”. Ora, essa foi a origem da Matemática Moderna. Estudaram-se as estruturas operatórias da inteligência? Não. Estudaram-se os preceitos de Vygotski? [...] Procuraram estudar, um pouco mais tarde, Gardner? Não, de jeito nenhum. Mas se impuseram os trabalhos de Matemática, principalmente do SMSG, onde foi trabalhar o nosso amigo Lafayette de Moraes. E nós? Sim. Mas para fazer aquela mudança era preciso uma linguagem, era preciso uma linguagem para entender esta nova Matemática. Então, nada melhor do que a linguagem que havia sido colocada, trabalhada e tratada nos fascículos com os resultados do grupo Bourbaki, após 1945. Então a linguagem era a teoria dos conjuntos. Portanto, coitados dos professores formados no Brasil (DI PIERRO NETTO, apud GARNICA, 2008, p. 197-198).

Também à semelhança de Lourdes, Scipione refere-se à Matemática Moderna como imposição:

Então, professores saídos das Licenciaturas Curtas eram obrigados a trabalhar com a Matemática Moderna, com a estrutura de grupo. Então decoravam ANIC (sim, porque é associativa, existe elemento neutro, existe inverso e é comutativa, então o grupo é abeliano) (DI PIERRO NETTO, apud GARNICA, 2008, p. 198). 
Do seu lugar de espectador, Scipione declara que não conhece algumas referências mencionadas por Martha Dantas: "Esses subsídios - gostaria de conhecê-los todos, que não os conheço - e eles devem ser divulgados para se saber do trabalho que se tentou fazer." (DI PIERRO NETTO, apud GARNICA, 2008, p. 198).

E ainda, diferente de Lourdes, Scipione faz referência a aspectos progressistas e efeitos positivos da Matemática Moderna, mesclados aos aspectos negativos e até desastrosos:

Coisas horrorosas se fizeram. Agora, as coisas boas é preciso dizer. O estudo da teoria das funções, cuidadoso, como é feito hoje, não era feito antes de se introduzir a Matemática Moderna. Mas isso é um produto principalmente para a escola média, não para a escola fundamental. $\mathrm{O}$ estudo das matrizes e o desenvolvimento dos estudos das matrizes foi provavelmente uma das coisas novas que se fizeram. Também se fizeram algumas coisas boas na Combinatória e na Teoria das Probabilidades. É preciso reconhecer que certos estudos se aperfeiçoaram, mas principalmente na escola média. $\mathrm{Na}$ escola fundamental nós tivemos um desastre em que o aluno sabia o que era interseção, sabia o que era reunião, desenhava perfeitamente os conjuntos que eram complementares, mas ele não sabia quanto era 7 vezes 8 . Então uma coisa que se disse: “Agora com a Matemática Moderna não é preciso mais saber a tabuada". Não precisa mais saber a tabuada! Como você não vai saber a tabuada? Como é que eu faço as continhas? Não é verdade. [...] Então, minha gente, coisas muito ruins foram feitas. Publicações boas; algumas, sérias. Outras não tão boas (DI PIERRO NETTO, apud GARNICA, 2008, p. 198-199).

Compartilhando confidências de tempos idos, Scipione relata um episódio envolvendo a publicação de um livro didático:

Não sei quantos se lembram de um livro, de um autor que apareceu como autor, que não era professor, não freqüentou o GEEM, nunca tinha aparecido... vou até citar o nome dele: professor Orlando Zambuzi. Publicou um livro por uma boa editora de São Paulo: Matemática Moderna. Aí, meu Deus do céu... Mas um livro tão errado, tão errado, tão errado, que o nosso prezado professor Castrucci não agüentou e falou assim: "Scipione, eu vou falar com o editor". Ele foi até o editor e disse: "Não pode colocar essas coisas...". Ele somava conjuntos, qualquer tipo de conjunto, fossem disjuntos, não fossem, enfim, essas coisas mais horrorosas. E o livro foi o livro que mais vendeu durante anos. E em razão das advertências do professor Benedito Castrucci ao editor, o editor foi sério a ponto de, no ano seguinte, não aprovar mais reedições desse livro, até porque um conhecedor da Matemática, sério em relação aos trabalhos que se faziam para renovação da Matemática, foi capaz de influir a esse ponto: sair da sua cátedra, sair de sua casa para conversar com o editor (que por sinal é um médico bastante responsável e competente, e foi capaz de não publicar mais esse livro) (DI PIERRO NETTO, apud GARNICA, 2008, p. 199-200).

Em outra confidência, evoca um episódio em que teria questionado o trabalho então desenvolvido pela equipe da UFBA:

Mas quantos professores existiam no Brasil, no estado de São Paulo (eu sabia que havia muito poucos naquela época), capazes de ministrar um curso através de construções geométricas? O grupo da Bahia escreveu um livro sério a respeito disso. E encontrou dificuldades sérias. Uma vez eu fui fazer uma palestra na Bahia e num auditório cheio, transbordando pelas janelas, pelas portas, escadas, me perguntaram sobre a possibilidade de trabalhar com livro dessa natureza. Eu disse: "Um livro bom 
e sério, mas eu acho ele difícil”. E eu fui culpado de ter dito que o livro era difícil. Esse livro era publicado, era assinado pela professora Martha Maria de Souza Dantas e pelo professor Omar Catunda, um livro da maior seriedade, mas que exigia um conceito que os alunos fossem capazes de entender - o conceito de vetor - e que trabalhassem através de construções geométricas. Isso pressupõe um outro tipo de professor, não o professor que nós tínhamos em São Paulo (DI PIERRO NETTO, apud GARNICA, 2008, p. 201).

A confidência dá início a uma mudança de tom em que as contribuições da Matemática Moderna são minimizadas e os efeitos indesejados reiterados:

Então, minha gente, nós tivemos problemas sérios com a Matemática Moderna. O pior que aconteceu foi que ela retirou certas coisas que eram seguras. Trabalhava-se a Geometria Euclidiana, e trabalhava-se com alguma seriedade ou com muita seriedade. Porque as estruturas operatórias da inteligência mostram (e isso é comprovado) que a partir dos doze anos e meio, ou até antes, os alunos são capazes de fazer deduções, e o processo dedutivo é um processo indispensável ao aprendizado em Matemática. Não se pode apenas fazer induções, fazer trabalhos, trabalhar com cálculos, apenas. É preciso que o aluno seja capaz de entender a relação "se p, então q", que ele seja capaz de deduzir, mesmo que sejam as coisas muito fáceis, usando a base do triângulo isósceles... são iguais ou congruentes?, e daí por diante. Mas hoje não se faz mais nada disso. Sabe por quê? São conseqüências da Matemática Moderna, que tirou aquela seriedade que existia no ensino da Matemática e que não foi capaz de repor tudo, embora tenha tido algumas que foram boas, mas sempre do ponto de vista do ensino médio. Para o ensino fundamental as coisas que se fizeram não trouxeram produtos desejáveis (DI PIERRO NET'TO, apud GARNICA, 2008, p. 201).

Novamente aproximando-se de Lourdes, Scipione se apresenta como alguém que sabe o desenrolar de uma história que ainda não aconteceu. Enquanto ela afirma que previra o que se passou depois, ele é assertivo acerca do que teria acontecido, se não tivesse havido adesão à Matemática Moderna, ou a determinadas versões da Matemática Moderna:

Nós fizemos muito boas conquistas, mas se ela não tivesse aparecido, se os americanos não tivessem levado aquele grande susto, essas outras conquistas teriam acontecido, porque o mundo não é tolo, não é constituído somente de pessoas que são capazes de copiar, que podem copiar ou devem copiar experiências de terceiros. Nós temos possibilidade de fazer bastante coisa e temos mostrado isso (DI PIERRO NET'TO, apud GARNICA, 2008, p. 201).

Rui Madsen Barbosa inicia sua manifestação corroborando as críticas à produção de livros didáticos que avalia como inconsistentes, que teria sido incentivada pelo movimento da Matemática Moderna. Traz o tema da escola primária, e faz referência ao universo marcadamente feminino, mencionando as "autoras" dos livros dirigidos a essa etapa, "várias assim":

[...] entre os defeitos que surgiram na época, eu me lembro naquela ânsia que tomou posse de autores, inclusive de autores que não eram de Matemática e, sim, autores de Matemática para a escola primária. Eu me lembro que, em menos de dois anos, começaram a surgir publicações de gente - se me permitem dizer - incapaz... Tanto o livro da primeira, segunda, terceira, quarta séries; essas autoras (foram várias assim), se também tivessem livros para o ensino da quinta à oitava, teriam também posto, 
em todos eles, conjuntos. Então nós encontramos conjuntos tratados em todas as séries e isto, é claro, foi demais de prejudicial (BARBOSA, apud GARNICA, 2008, p. 202).

Ele continua, em tom de relato, sugerindo mas não explicitando que teria se engajado no movimento:

Eu me lembro bem que se falava em algo ruim na teoria dos conjuntos. Surgiram até dois termos muito conhecidos: conjuntite e um que cabe bem agora para o Brasil: conjuntivite. Mesmo quem não tinha dado aula tinha aprendido um pouco, porque o Grupo de Estudo em Ensino da Matemática se propôs, logo no seu início, a divulgar e - a verdade seja dita -, com a colaboração, com o apoio, da própria Secretaria de Educação. E nesses cursos, então, as pessoas aprendiam e imediatamente iam usar, é claro. E usaram em todas as séries. Algumas outras coisas parecidas também aconteceram. Nessa ânsia, apareceu, em Lógica, o uso das famosas tabelas-verdade. E isso foi outra doença também. Quer dizer, era só fazer tabela-verdade: isso era fazer Lógica. Vocês devem estar lembrados que o primeiro que lhes falou [prof. Lafayette] lembrou, por exemplo, do estudo das matrizes, e eu complementaria, dizendo que as coisas devem ser entendidas. Por quê? Porque, na época, se estudava a teoria dos determinantes com uma quantidade enorme de teoremas. Então, uma das preocupações, aqui no Brasil, também foi a substituição, quase que completa, na teoria dos determinantes, pelas matrizes e os seus métodos, para aplicar em sistemas lineares (BARBOSA, apud GARNICA, 2008, p. 202).

A implicação de Rui no movimento fica mais explícita pela referência a um episódio anedótico:

Só para vocês terem uma idéia eu lhes conto uma passagem que aconteceu num Congresso de Belém, no Pará. O professor Callioli foi apresentar como resolver sistemas lineares sem usar determinantes. E um matemático local, que tinha feito seus estudos no IMPA, coincidentemente meu xará, desafiou, em público, que houvesse alguém que fosse capaz de resolver sistemas lineares sem usar os determinantes. Eu - como em geral sou um pouco metido -, eu me ofereci, então, que eu faria isso. E qualquer dos meus alunos. E no dia seguinte os jornais notificaram como manchete "Rui contra Rui"... E felizmente eu não precisei mostrar porque ele foi lendo e viu que era possível, e tudo que ele fez, com uma pilha de livros, foi demonstrar que, de fato, era possível... recuou... (BARBOSA, apud GARNICA, 2008, p. 202-203).

$\mathrm{Na}$ sua interpretação, os efeitos indesejáveis da Matemática Moderna eram inevitáveis ou intrínsecos à movimentação: "Então vocês têm que entender que, naquela época, houve as coisas ruins, que foram gerais em todos os países" (BARBOSA, apud GARNICA, 2008, p. 204).

Rui então, sugere, mas não explicita, uma agência que teria produzido efeitos desejáveis e indesejáveis, como que reivindicando que ambos fossem considerados em uma espécie de balanço geral do movimento:

Aqui, isso ocorreu com alguns agravamentos, em função desta pressa de se publicar coisas sem o devido trabalho experimental. Foram feitas pesquisas? Foram, mas poucas. Não daria para se experimentar todas as coisas. Algumas coisas ficaram. O Scipione, por exemplo, lembrou dos aspectos de Probabilidade, por exemplo, que vocês têm usado muito, tanto na Combinatória como nas Probabilidades: as árvores de possibilidades e probabilidades são dessa época. Antes não se fazia dessa maneira. 
A linguagem. A própria linguagem ficou. Não é que a teoria dos conjuntos esteja errada ou que seja ruim, tanto é que vocês ainda usam essa linguagem de uma maneira mais suave, não é? Então todas estas coisas têm que ser entendidas. Houve entre nós esses agravamentos (BARBOSA, apud GARNICA, 2008, p. 204).

\section{Mesa-redonda - a segunda rodada de manifestações}

É interessante trazer, também, extratos da segunda rodada de manifestações, isto é, da fala de alguns participantes em diálogo com ou a partir das manifestações dos colegas. Nessa segunda rodada, alguns trazem novas informações, precisando ou desenvolvendo reflexões e argumentos; outros retificam ou apresentam nuanças em suas avaliações. Pois, como lembra Bakhtin (2014), todo enunciado visa um interlocutor, o que dizemos, o dizemos para alguém ou alguéns.

Lafayette de Moraes, mais uma vez, situa-se como alguém engajado no movimento da Matemática Moderna - ainda que um agente discreto, como um coadjuvante. Traz uma tonalidade nova aos testemunhos, refletindo sobre os efeitos dessa participação em sua própria trajetória. Nessa reflexão, faz duas referências ao imprevisto - o golpe de 1964 e um encontro não planejado:

Eu posso dizer que, no meu caso particular, evidentemente, abriu horizontes que seriam impensáveis antes disso. A partir daqueles estudos que eu fiz nos Estados Unidos, na volta, por coincidência, nesse congresso de São José [São José dos Campos, em 1966], e eu encontrei o professor Newton da Costa, que todo mundo conhece aqui - é um dos fundadores da lógica paraconsistente. [...] Tinham acabado de acontecer as coisas em 64, e eu tinha saído da USP. [...] Em síntese, daí surgiu o Grupo de Lógica de Campinas, eu fiz o mestrado, o doutorado, e foi por aí. Sob esse ponto de vista, quer dizer, se eu também não tivesse tomado contato, da maneira que eu tomei, com a nova estrutura e visão da Matemática, eu jamais teria podido me aproximar do professor Newton para conversar alguma coisa, menos ainda para dizer quais eram minhas pretensões. Portanto, nesse caso particular, foi isso (MORAES, apud GARNICA, 2008, p. 204-205).

Lourdes Onuchic, reiterando sua avaliação crítica, apresenta nuâncias, elogiando as intenções do GEEM:

Eu gostaria de voltar a falar do GEEM, porque o grupo trabalhava, era um grupo assíduo, que queria mesmo trabalhar e melhorar as coisas. E como pegou a ocasião da Matemática Moderna, então isto foi muito explorado. O professor Sangiorgi trazia muita gente de fora, fazia cursos - que duravam semanas, às vezes - para aprender aquelas coisas todas. Foi um período fértil que a gente não pode dizer que não tenha tido valor. Muita coisa foi feita. Mas, como eu já disse, os estragos que aconteceram por não se ouvir os professores nenhuma vez... Então não podemos dizer que não houvesse nada de bom na Matemática Moderna. O que eu realmente critico há algum tempo é que em todas as vezes os professores não eram ouvidos, e não foram ouvidos também nesta vez. E agora, fruto de muita cabeçada, nós estamos vendo que é preciso ouvir os professores, aqueles que têm as salas de aula. Saber o que eles pensam, como eles ensinam, como eles pensam, quais são suas crenças, o que fazer para poder ensinar. A Matemática Moderna deu também a sua contribuição (ONUCHIC, apud GARNICA, 2008, p. 205-206). 
Em sua segunda manifestação, Martha Dantas dialoga com a alegação de que a Matemática Moderna teria sido imposta aos professores, replicando que a imposição teria ocorrido na supressão dos projetos:

\begin{abstract}
Mas o fato é que a Matemática [Moderna] veio para ficar. Agora, uma coisa é ensinar Matemática Moderna em nível superior e outra é o nível médio. Mas nós temos caminhos para isso. O caminho, o grande caminho, é o da pesquisa. Nós não impusemos na Bahia o ensino da Matemática Moderna em colégio algum. As pessoas vinham a nós e pediam que nós fôssemos trabalhar, fazer a experiência lá. Houve uma experiência que durou nove anos. E agora, sem conhecerem a experiência (uma experiência no colégio do SESI), sem conhecerem a experiência, tiraram os livros, acabaram com o projeto, com o trabalho que estava se fazendo lá, que não era de Matemática Moderna, mas tinha o ensino da Geometria através das transformações, da Geometria Euclidiana. E foi assim que os meninos começaram a aprender Geometria (DANTAS, apud GARNICA, 2008, p. 207).
\end{abstract}

Sobre a imputação de que a Matemática Moderna teria sido responsável pela eliminação do estudo da geometria dedutiva, Martha diverge de Scipione:

Eu discordo do professor Scipione porque, quando eu comecei a trabalhar, a Geometria já estava desaparecendo dos currículos. E depois chegou ao ponto de, nos livros, até mesmo nos livros de professores competentes, estar somente "hipótese e tese", e "quem diz Matemática diz demonstração". Eu fui convidada para examinar uma tese na PUC de São Paulo que era "Geometria com demonstração" porque a pessoa que elaborou a tese mostrava que não se estava demonstrando. Então, não foi culpa da Matemática Moderna, não foi por isso. Pelo contrário, ela ajudou a apresentar possibilidades como, por exemplo, a de trabalhar com a Geometria Euclidiana utilizando as transformações geométricas (DANTAS, apud GARNICA, 2008, p. 207).

Martha reitera a importância da pesquisa e o modo como foi considerada pela equipe da UFBA:

Então, o que eu acho é que é preciso pesquisar primeiro para depois então adotar. Ao substituirmos o projeto em que nós estávamos trabalhando por um outro projeto (o projeto que eu não tive a oportunidade de apresentar aqui), nós mantivemos noções de conjuntos; nós mantivemos também até alguma coisa sobre estrutura porque, inclusive, os professores, os físicos, por exemplo, eles me dizem que estão tendo muito trabalho porque eles precisam trabalhar com as estruturas (e não só com as estruturas de grupo não, anéis e outras estruturas mais). Então nós achávamos que até mesmo no curso de colégio era preciso que se fizesse alguma coisa pra ver se ajudava a preencher esse fosso, que realmente existe (DANTAS, apud GARNICA, 2008, p. 207-8).

E finaliza reiterando sua compreensão da atualidade da Matemática Moderna:

Eu acho que já falei bastante e só queria dizer que nós precisamos continuar pesquisando para ver o que podemos colocar de Matemática Moderna nos nossos currículos (DANTAS, apud GARNICA, 2008, p. 208).

Scipione inicia sua fala concordando com Martha a respeito da geometria e desdizendo comentário anterior: 
Só queria dizer que eu concordo com a professora Martha, caso não tenha me expressado bem e tenha ficado a impressão de que se abandonou a idéia de demonstração (pela qual eu acho que se faz realmente Matemática), e ficou parecendo que a Matemática Moderna tem culpa disso. Não tem culpa disso (DI PIERRO NETTO, apud GARNICA, 2008, p. 208).

E narra outro episódio anedótico, em que finalmente aparece como personagem, um personagem que tenta resistir às pressões editoriais:

Só queria contar um fato curioso. Havia tanta paixão, tanto interesse, interesse comercial, que o meu primeiro editor, em 1967, diz: "Não, seu livro vai chamar Matemática Moderna", e eu disse: "Nunca, não tem que chamar Matemática Moderna", eu falava: "Jamais". Aí um dia eu telefonei para ele e falei: "Paulinho", ele chama-se Paulo, "Paulinho, eu descobri um título para colocar no livro: Matemática para escola moderna". Ele falou: "Ótimo, Scipione, ótimo. A gente põe 'Matemática' com letra grande, 'para a escola' em letra pequenininha, e 'Moderna' em letra grande”. (risos). Por aí vocês vêem o interesse comercial como era. E eu não consegui demover o editor... o "para a escola" ficou bem pequeno. (risos) (DI PIERRO NETTO, apud GARNICA, 2008, p. 208).

Após a segunda rodada, os palestrantes respondem ou comentam manifestações do público.

Lafayette responde uma questão sobre "transferência" ou "imposição de conhecimento" construindo uma perspectiva temporal mais ampla:

Agora, acontece o seguinte, precisamos nos transportar para praticamente meio século atrás. E, de fato, ocorre até hoje, vamos dizer assim, a influência dos Estados Unidos é extremamente grande. A influência dos estrangeiros sempre foi muito grande aqui. A Faculdade de Filosofia de São Paulo teve grande influência de professores italianos e franceses; no ITA teve um grande professor que era o Murnagham, a quem o professor Ubiratan se referiu ontem, professor americano, que praticamente formou todo o currículo do ITA e dava ênfase, por exemplo, a um livro de Geometria Analítica cujo enfoque era inteiramente novo para nós e causou um grande impacto. Portanto, essa hegemonia que hoje a gente sabe, há cinqüenta anos não era tão evidente, era assim manifestada de uma maneira mais subjacente, não tão aparente (MORAES, apud GARNICA, 2008, p. 209).

As falas finais retomam comentários sobre a importância da formação de professores, problemas e livros didáticos, mais relacionados com o momento de realização do debate.

\section{Quem éramos nós?}

Relendo os extratos das falas dos professores, percebemos que o estranhamento de si, no passado, é rarefeito.

Para Scipione e Rui, o personagem do passado - "quem eu era" - está quase ausente. Em suas falas, assemelham-se aos narradores dos romances realistas, que, invisíveis, tudo veem. Lourdes apresenta-se como sendo a versão recente do personagem de outrora, sempre preocupado em ouvir os professores e rejeitando mudanças abruptas ou unilaterais. Os três professores referem-se aos anos 1960 como se os problemas então 
vividos fossem os mesmos com os quais os educadores matemáticos se deparavam à época da mesa-redonda. Até a reticência em falar de si e das escolhas que fizeram denota uma suspensão da passagem do tempo - pois parecem esquivar-se de julgarem a si próprios, como se ainda fossem os mesmos professores.

Lafayette e Martha apresentam-se como agentes da Matemática Moderna, e estabelecem conexões entre suas próprias trajetórias, eventos dos anos 1960 e suas repercussões. Martha revela-se agente de uma obra inacabada: de um lado, porque as experimentações coordenadas pela equipe da UFBA foram cerceadas; de outro lado, porque o debate sobre a Matemática Moderna, que ela reivindica, foi em parte interrompido, em parte atravessado por impressionismos e imprecisões. Dentre todos, Lafayette é o que revela mais distanciamento do passado; trata da Matemática Moderna como um tema do passado.

Pensando, como propõe Hannah Arendt, que o "quem” da ação revela-se para o historiador - que pode perceber e pensar, retrospectivamente, sobre uma teia de eventos e até mesmo para alguns contemporâneos, mas não para o sujeito que age, percebemos que a Matemática Moderna não era, para aqueles professores, um processo encerrado. $\mathrm{O}$ que é curioso, considerando os discursos que, trinta anos antes, haviam decretado o "fracasso" do movimento.

Ainda, observamos que ao longo do debate, Lourdes, Scipione e Rui revisam sua narrativa, indicando aspectos positivos da Matemática Moderna e reconhecendo que havia deixado marcas importantes nos currículos escolares praticados no Brasil.

Esse recuo parece se dever, sobretudo, à exigência apresentada por Martha de que a Matemática Moderna fosse tratada como uma ação empreendida por educadores brasileiros.

O discurso que descreve a Matemática Moderna como reação norte-americana ao avanço tecnológico soviético, depois "transferida" para o Brasil e para outros países, também é refutado por Martha, que recorda os trabalhos da CIEAEM, anteriores ao tão comentado lançamento do satélite Sputnik. Mas a existência de diferentes vertentes do movimento é negligenciada pelos interlocutores, que se referem à Matemática Moderna como uma onda disforme que arrastou consigo variados personagens. As diferenças entre os textos do matemático belga Georges Papy e do SMSG, por exemplo, não são por eles consideradas relevantes - os textos de Papy são genericamente descritos, nos comentários de Lourdes e Scipione, como inadequados para a educação escolar. Lafayette problematiza a explicação da Matemática Moderna como "transferência" de propostas curriculares, lembrando que a impregnação de modelos europeus no ensino de Matemática no Brasil é anterior aos anos 1960. Mas essa observação não é retomada pelos pares.

Arriscando uma miscelânea de enfoques teóricos, penso que a dificuldade ou, talvez, impossibilidade do estranhamento dos professores em relação àqueles que os precederam - versões de si no passado - corrobora o artificialismo do discurso (auto)biográfico denunciado por Bourdieu. Pois percebe-se uma tendência não apenas a introduzir falsos elos entre diferentes momentos da trajetória de cada um(a), mas a borrar a dimensão temporal, como se tudo tivesse acontecido ao mesmo tempo ou em tempo nenhum. 
A questão “Quem éramos?” está, de algum modo, presente nas falas de Martha e Lafayette. Mas, ainda engajada na defesa da Matemática Moderna, Martha ocupa-se de defender as escolhas que fez no passado e que considera ainda atuais.

Será ou não por acaso? Afinal, nestas últimas linhas, ocupamo-nos do tema... Será por acaso que é Lafayette, mais distante do professor que foi nos anos 1960, quem evoca as expressões "sorte" e "coincidência"? A probabilidade diz que não! Uma explicação possível é a de que o estranhamento seria condição para percebermos a história - e em particular aquela da qual somos personagens e, talvez, agentes - como um emaranhado de ações, reações, escolhas e acasos. Lafayette escolheu engajar-se na tradução e adaptação de livros, mas essa escolha foi possível, reconhece ele, porque trabalhava então na FUNBEC.

Martha refere-se ao acaso, mas não de modo explícito. Pois, na trama que narra, seria preciso que Omar Catunda tivesse ido a Salvador em 1955 para que, anos mais tarde, aceitasse ser diretor do IMF da UFBA; e ele poderia ter tido muitos motivos para não ir a Salvador, enquanto o próprio evento era, como já argumentamos, improvável. Como teria sido o engajamento de Martha na Matemática Moderna, sem a parceria de Omar Catunda? Ela não se arrisca a "prever" o que poderia ter sido, como fazem Lourdes e Scipione. Mas situa suas escolhas entre os possíveis do momento e das condições em que trabalhava.

Hannah Arendt fala-nos da ação como a realização do improvável. Improvável, porque não é determinada pelo que a precede. Envolve gestos, apostas e escolhas de direção e sentido, de momento e de modo, mas não escolhas sobre os resultados, porque os resultados são constituídos nas relações humanas, e por isso são imprevisíveis. Para Hannah Arendt, quem age não sabe ainda quem é; mas talvez quem age possa vir a saber. Pois poderá interrogar-se e ver-se a si mesmo, como personagem de uma trama. E ao desemaranhar essa trama, poderá perceber a interveniência de outros, das contingências e dos acasos, pois com eles se confrontou. Já quem opina, mas se exime de agir, talvez nem perceba o tempo passar.

Quem éramos nós, professores modernos de Matemática? Ou, quem somos nós? Os testemunhos dos professores, em 2003, nos dão algumas pistas sobre como veremos a nós mesmos, em 2023, ou depois. Se estivermos vivos.

\section{Referências}

ARENDT, H. A condição humana. Rio de Janeiro: Forense Universitária, 2007.

BAKHTIN, M. Marxismo e filosofia da linguagem: problemas fundamentais do método sociológico na ciência da linguagem. São Paulo: Hucitec, 2014.

BEGLE, E. G. The School Mathematics Study Group. The bulletin of the National Association of Secondary School Principals, Reston (EUA), v. 43, n. 247, p. 26-31, maio 1959.

BOURDIEU, P. A ilusão biográfica. In: AMADO, J.; FERREIRA, M. M. (Org.). Usos

\& abusos da história oral. Rio de Janeiro: Editora FGV, 2006. p. 183-191. 
BÚRIGO, E. Z. Movimento da Matemática Moderna no Brasil: estudo da ação e do pensamento de educadores matemáticos nos anos 60. 1990. 286 f. Dissertação (Mestrado em Educação) - Faculdade de Educação, Universidade Federal do Rio Grande do Sul, Porto Alegre, 1989.

GARNICA, A. V. M. Resgatando oralidades para a história da Matemática e da Educação Matemática brasileiras: o Movimento Matemática Moderna. Zetetiké, Campinas, v. 16, n. 30, p. 163-217, jul./dez. 2008.

OLIVEIRA, M. da G. Quem tem medo da ilusão biográfica? Indivíduo, tempo e histórias de vida. Topoi, Rio de Janeiro, v. 18, n. 35, p. 429-446, maio/ago. 2017. 